\title{
A review of the subfamily Anobinae with the description of a new species of Baniana Walker from North and Central America (Lepidoptera, Erebidae, Anobinae)
}

\author{
J. Donald Lafontaine ${ }^{1, \dagger}$, J. Bruce Walsh $h^{2, \ddagger}$ \\ I Canadian National Collection of Insects, Arachnids, and Nematodes, Biodiversity Program, Agriculture and \\ Agri-Food Canada, KW Neatby Bldg., C.E.F., Ottawa, Ontario, Canada K1A OC6 2 Dept of Ecology and \\ Evolutionary Biology, Biosciences West, University of Arizona Tucson, AZ USA 85721; Research Associate: \\ McGuire Center for Lepidoptera and Biodiversity, Florida Museum of Natural History, University of Florida, \\ Gainesville, Florida, USA \\ † urn:lsid:zoobank.org:author:2227A860-B768-4A51-8FE4-F1F3EB1CAA7F \\ $\ddagger$ urn:lsid:zoobank.org:author:EFCD84CA-F880-4BC5-8AEC-BF2C7323920B \\ Corresponding authors: J. Donald Lafontaine (Don.Lafontaine@agr.gc.ca), J. BruceWalsh (jbwalsh@u.ari- \\ zona.edu) \\ Academic editor: Christian Schmidt $\mid$ Received 12 February 2010 | Accepted 24February 2010 | Published 18 March 2010 \\ urn:lsid:zoobank.org:pub:7949C108-5A98-4A06-8BDD-F4D42EA95E52 \\ Citation: Lafontaine JD, Walsh JB (2010) A review of the subfamily Anobinae with the description of a new species of \\ Baniana Walker from North and Central America (Lepidoptera, Erebidae, Anobinae). In: Schmidt BC, Lafontaine JD \\ (Eds) Contributions to the systematics of New World macro-moths II. ZooKeys 39: 3-11. doi: 10.3897/zookeys.39.428
}

\begin{abstract}
A new species of Baniana Walker related to B. gobar Druce is described from Arizona and Costa Rica and the status of Baniana, Anoba Walker, and the Anobinae are discussed. Adults and/or genitalia of Anoba trigonoides Walker, Anoba sp. trigonoides group, Baniana significans Walker, B. minor sp. n., B. gobar, and Deinopa delinquens (Walker) are illustrated.
\end{abstract}

\section{Keywords}

Taxonomy, Anobinae, Anoba trigonoides, Baniana minor, Baniana gobar, Baniana significans, Deinopa, Arizona, Costa Rica, Dominican Republic, Mexico, Venezuela

Copyright J.D. Lafontaine, J.B.Walsh. This is an open access article distributed under the terms of the Creative Commons Attribution License, which permits unrestricted use, distribution, and reproduction in any medium, provided the original author and source are credited. 


\section{Introduction}

The Anobini was proposed by Holloway (2005) for Anoba Walker and related genera that share various features of habitus and genital structure. Several genera are sexually dimorphic, so the males and females were sometimes described as separate species. An undescribed species of Baniana Walker occurs from Arizona to Costa Rica, so the subfamily and associated genera are briefly diagnosed in order to include the Anobinae and the genera Baniana and Deinopa Walker in the North American check list (Lafontaine and Schmidt 2010).

\section{Materials and methods}

\section{Repository abbreviations}

Specimens were examined from the following collections:

BMNH The Natural History Museum (statutorily, British Museum (Natural History)), London, UK

CDF Personal Collection of Clifford D. Ferris, Laramie, Wyoming, USA.

CNC Canadian National Collection of Insects, Arachnids, and Nematodes, Ottawa, Ontario, Canada.

JBS Personal collection of J. Bolling Sullivan, Beaufort, North Carolina, USA.

JBW Personal collection of J. Bruce Walsh, Tucson, Arizona, USA.

USNM National Museum of Natural History (formerly, United States National Museum), Washington, District of Columbia, USA.

Dissecting methods and genital terminology. Dissection of genitalia and terms for genital structures and wing markings follow Lafontaine (2004).

\section{Subfamily Anobinae Holloway, 2005, stat. rev.}

Type genus: Anoba Walker, 1858

The classification of the recently proposed subfamily Anobinae (Holloway 2005) is poorly understood. It appears that none of the genera is shared by the New World and Old World faunas, in spite of strikingly similar appearances among some species and current generic assignments. In the New World the generic classification is very confused. Four genera are associated with Anobinae in the New World: Anoba Walker, Baniana Walker, Deinopa Walker, and Lephana Walker. In all genera of Anobinae the head and prothoracic collar are dark and contrast with the color of the thorax, and the middle of the male valva has a lightly sclerotized "window," usually in the same area as the clasper. Males have bipectinate antennae, or the seta on each side of the flagellomeres is enlarged giving the impression that the antenna is narrowly bipectinate. 
Of 41 species associated with the genus Anoba by Poole (1989), only seven occur in the New World and only three of these are referable to Anoba (A. pohli (Felder \& Rogenhofer), A. trigonoides Walker [the type species of Anoba], and A. uncifera Hampson). Two others belong to Baniana (B. crucilla (Schaus) comb. n. and B. firmalis (Guenée), comb. n.), with the remainder belonging elsewhere. All of the Old World species need to be relegated to Old World genera.

Of 44 species listed in Baniana by Poole, 34 occur in the New World, but only five of these are referable to Baniana (B. gobar Druce, B. haga Schaus, B. inaequalis Walker, $B$. significans Walker [the type species of Baniana], and B. triangulifera Dognin). Most of the remaining 29 New World species belong to the Deinopa generic complex.

Poole lists 17 species of Deinopa of which 13 occur in the New World. These 13, together with most of the 29 species currently misplaced in Baniana, form a generic complex that has not yet been resolved. As an example of the structural heterogeneity of the group, the male genitalia of Deinopa delinquens Walker, type species of the generic "synonym" Poesula Walker, is illustrated (Fig. 10).

Poole lists six species of Lephana, although additional species are misplaced in other genera. Lephana is characterized by the prominently falcate forewing apex, and a triangular patch of scales projecting below the hind margin of the forewing wing at the antemedial line.

Among the New World Anobinae, species in the genus Baniana are likely to be confused only with those in Anoba. In both genera the male antenna is bipectinate, the forewing is broadly triangular with a slightly falcate apex, there is a velvety-black patch on the outer margin of the antemedial (am) line. The two genera are most easily separated according to sex, because Anoba is sexually dimorphic.

In Baniana males (Figs 3, 4, 6, 7) the black patch on the outer side of the antemedial line is largest near the middle of the line, and the postmedial (pm) line is deeply incurved near the middle of the wing to a position below the reniform spot with dark shading along the outer margin of the line. The female (Figs 5,8) is similar in pattern to the male, but the antennal flagellomeres are bead-like, not bifasciculate.

In the male of Anoba (Fig. 1) the black patch in the medial area forms a triangle (one side on the am line, one on the posterior margin of wing, and one from the am line to the pm line); the pm line is similar to those of Baniana males. In the female of Anoba (Fig. 2) the black patch on the am line is similar to that in Baniana males, but the pm line is straight or slightly sinuate and without dark shading in subterminal area.

\section{Baniana Walker, 1858}

Type species. Baniana significans Walker, 1858 by monotypy.

Diagnosis. Adults. Males and females of similar size and pattern; forewing length 7-15 mm. Head - Labial palpus with third segment short and rounded, 0.20-0.25 × as long as second segment. Lower frons usually denuded of scales. Male antenna bipec- 
tinate; female antenna bead-like, appearing slightly biserrate dorsally because scales on shaft flare out anteriorly over base of flagellomeres. Head and prothoracic collar black, dark brown, or reddish brown, contrasting with brown or gray color of thorax. Thorax - Tibia without spiniform setae; tibia smoothly scaled with longer hair-like scales but without hair pencils. Forewing broad and triangular, apex slightly falcate; antemedial line with black lobe or enlargement near middle of outer side; postmedial line curved inward and upward to touch bottom of reniform spot; reniform spot reduced to two black dots, sometimes connected; orbicular spot, if present, a small black dot . Hindwing fuscous. Male genitalia - Upper part of tegumen enlarged into hood-like posterior projection; uncus elongate, with projecting flanges or processes. Valva with heavily sclerotized plates, flanges, or processes on costal and/or ventral margin of valve; central part of valva with lightly sclerotized translucent "window;" valve tapered from base to apex and arching downward; clasper vestigial, a sclerotized plate in middle of valve distal to sacculus. Aedeagus varies from short and stout to slender and curved; vesica with numerous spinulose diverticula. Female genitalia - Corpus bursae very long with narrow posterior 3/4 resembling a ductus bursae; ductus seminalis at posterior end of ductus bursae on short appendix bursae; posterior part of ductus bursae sclerotized or with longitudinal sclerotized ridges; ostium and ductus bursae sclerotized; ostial opening on anterior margin of abdominal segment 8 (A8). A8 lightly sclerotized except for two postvaginal sclerotized plates in ventral wall of A8. Anterior apophyses slightly shorter than A8; posterior apophyses slightly longer than A8. Anal papillae as long as lateral width, truncated posteriorly, covered with short setae.

Included species. Baniana firmalis (Guenée), B. gobar Druce, B. haga Schaus, $B$. inaequalis Walker [= B. crucilla (Schaus), syn. n.], B. minor Lafontaine \& Walsh, sp. n., $B$. significans Walker, and B. triangulifera Dognin.

\section{Key to species of Baniana}

1. Postmedial line only slightly incurved below reniform spot; French Guiana, Brazil ..................................................................... B. inaequalis

- $\quad$ Postmedial line markedly incurved below reniform spot and bending upward toward reniform spot ........................................................... 2

2. Black shading on antemedial line merely an enlarged dark area tapered slightly to posterior margin of wing .......................................................... 3

- Black shading on antemedial line forming large rounded or wedge-shaped lobe extending into medial area from middle of antemedial line............... 4

3. Black shading on antemedial line prominent from costal margin of wing to posterior margin; ground color of forewing brown; French Guiana

B. firmalis

- Black shading on antemedial line tapered to thin line toward costal margin of wing; ground color of forewing gray; Costa Rica.......................... B. haga

4. Postmedial line covering reniform spot (i.e., no black dots above pm line); Argentina

- $\quad$ One or two black dots above postmedial line at position of reniform spot .....5 
5. Two black dots representing reniform spot (Fig. 3); forewing length: 12-14 mm; Dominican Republic

B. significans

- $\quad$ One black dot representing reniform spot; forewing length: $8-10 \mathrm{~mm}$...... 6

6. Black lobe on antemedial line extending about $1 / 2$ distance to postmedial line (Figs 7,8 ); uncus with dorsal crest-like ridge at $1 / 4$ from base (Fig. 12); posterior part of corpus bursae with longitudinally sclerotized ridges (Fig. 14); Durango, Mexico to Guanacaste, Costa Rica B. gobar

- Black lobe on antemedial line extending about $1 / 4$ distance to postmedial line (Figs 4-6); uncus with finger-like process ventrally at 1/3 from base (Fig. 11); posterior part of corpus bursae evenly sclerotized (Fig. 13); southeastern Arizona to Costa Rica

B. minor

\section{Systematics}

\section{Baniana minor Lafontaine \& Walsh, sp. $\mathrm{n}$.} urn:Isid:zoobank.org:act:26940137-FF02-4590-8ACA-4555715F9E39 Figs 4-6, 11, 13

Type material. Holotype male. Arizona, Santa Cruz Co., 4900', Patagonia Mts., Harshaw, UV/MV light, oak and mesquite grassland habitat, 29 Aug. 2006, B. Walsh leg., CNC Noctuoidea slide 15866, Barcote of Life voucher CNC Noctuoidea NOC14005. CNC. Paratypes: 2, 4 q . USA, Arizona. Same locality and collector as for holotype, 27, 28 Aug. 2007 (2 ठ), 13 July 2008 (3 ㅇ), J. B. Walsh leg.; Santa Cruz Co., Patagonia Mts., Harshaw area, 30 Aug. 2005, H. Grisham (1 +). Paratypes deposited in $\mathrm{CDF}, \mathrm{CNC}$, JBW.

Other material examined: Costa Rica, Guanacaste Prov., Santa Rosa National Park, 29-30 April 1980, D.H. Janzen \& W. Hallwachs ( $1 \overbrace{}^{\Uparrow})$. Costa Rica, Area de Conservacion de Guanacaste: Hotel Borinquen, 22 Sept. 2006, F. Quesada \& H. Cambronero (1 P); Sector Santa Rosa, 25 May 2007 (1 +); Sector Mundo Nuevo, 13 Nov. \& 9 Dec. 2007 (2 9 ), R. Franco \& H. Cambronero.

Etymology. The species name minor refers to the small size of this species of Baniana.

Diagnosis. Baniana minor can be recognized by its small size (forewing length: 8-9 $\mathrm{mm}$ ), the relatively short bulging black area near the middle of the antemedial line, and by the ventral subbasal process on the ventral margin of the uncus. Other differences in B. gobar are given in brackets in the description of B. minor.

Description. Adults. Male and female similar in size, color, and maculation. Forewing length: 8-9 mm. Head - Male antenna bipectinate, with longest rami $4 \times$ as wide as central shaft; apical seta long, $2 \times$ as long as central shaft and $1 / 2$ as long as rami. Female antenna bead-like, constricted between segments. Palpi appearing laterally flattened and blade-like with scale row ventrally and dorsally; apical segment short and rounded, $0.20-0.25 \times$ length of second segment. Scales narrow and strap-like, 


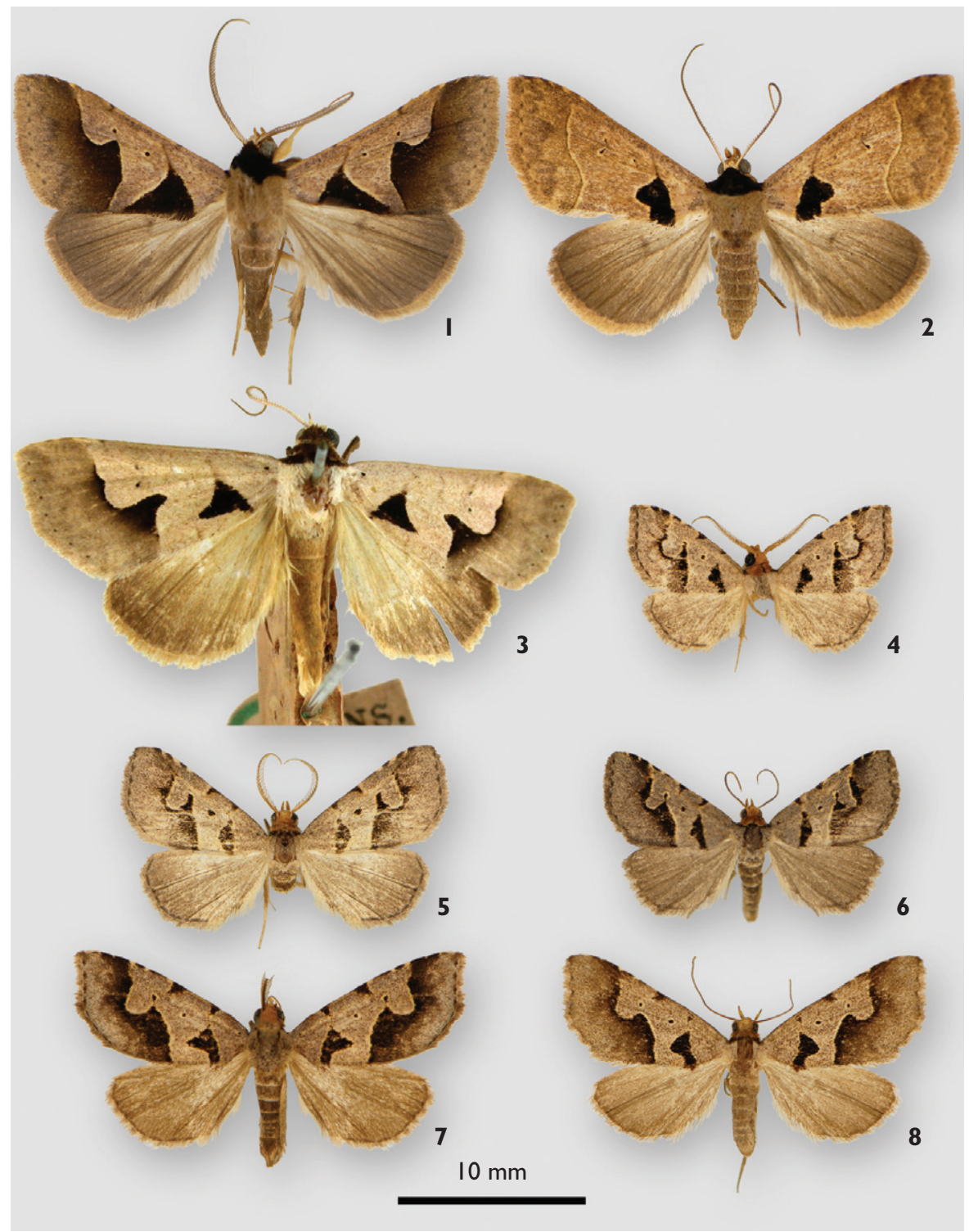

Figures I-8. Adults of Anobinae. I Anoba sp. trigonoides species complex, male (Paraguari, Paraguay) 2 Anoba sp. trigonoides species complex, female (Itapua, Paraguay) 3 Baniana significans male holotype (Santo Domingo, Dominican Republic) 4 Baniana minor male (Guanacaste, Costa Rica) 5 Baniana minor male paratype (Santa Cruz Co., Arizona, USA) 6 Baniana minor female paratype (Santa Cruz Co., Arizona, USA) 7 Baniana gobar male (Puebla, Mexico) 8 Baniana gobar female (Puebla, Mexico).

yellow brown on labial palpi and head, and reddish orange on prothoracic collar. Thorax-Covered with narrow strap-like scales, forming black transverse band posterior to prothoracic collar, pale gray brown elsewhere. Legs: Foretibia covered with pale reddishbrown scales; scales on middle and hind tibiae and tarsi with pale gray-brown scales 
with scattered dark-brown scales. Tibia without spiniform setae and without long tufts of scales. Wings: Dorsal forewing mainly gray with scattered brown scales; basal line absent; antemedial line with straight inner margin, outer margin bulging into medial area between anal and cubital vein, line obsolete in upper part of cell but reappearing as dark wedge on costa; second wedge-shaped spot on costa at position of medial line; orbicular spot a black dot in cell between two wedges on costa; reniform spot a black dot or teardrop-shaped spot above curve in postmedial line; postmedial line extending down from costa, parallel to outer margin of wing, curving abruptly inward at vein M3, then upward to touch or almost touch reniform spot, then extending down to posterior margin of wing slightly beyond middle of hind margin; postmedial line black with sharply-defined inner margin but diffuse outwardly with black and brown scales fading to mainly pale-gray scales in most of subterminal and terminal area; terminal line black, slightly enlarged between veins, broken at position of veins; fringe a mixture of pale-gray and dark-gray scales. Hindwing fuscous, slightly paler toward wing base in males; terminal line dark gray; fringe fuscous. Male genitalia - Uncus: basal 2/3 cylindrical with low, sclerotized mid-dorsal ridge [basally "winged" with lateral carinae in $B$. gobar]; a curved finger-like lobe projecting from ventral surface at $1 / 3$ from base [absent in $B$. gobar]; apical $1 / 3$ of uncus abruptly bent downward with apex dorsoventrally flat [evenly curved in $B$. gobar]. Tegumen broad, hood-like, projecting posteriorly. Saccus very short, with pointed anterior process. Juxta elongated, somewhat V-shaped with lower (anterior) extension tapered and lightly sclerotized; upper (posterior) extension divided into two heavily sclerotized processes covered with spines [spines absent in B. gobar]. Valve broad basally, evenly tapered and down-curved to apex; setose clavus-like process at base of costal margin of valve projecting $1 / 2$ distance across valve [projecting $1 / 4$ distance in $B$. gobar]; curved carina at apex of sacculus on left valve, angled and near middle of valve on right side [carinae at apex of sacculi on both valves but asymmetrical in $B$. gobar]; costal margin of valve evenly convex [costal margin with serrated fin-like process near middle and setose lobe at 3/4 in B. gobar]. Aedeagus cylindrical and straight [curved through 90 degree angle at $1 / 3$ from base and tapered to apex in B. gobar]. Female genitalia - Corpus bursae very long, $8 \times$ long as ductus bursae, but posterior 3/4 long and narrow, resembling a ductus bursae; ductus seminalis at posterior end of corpus bursae on a small appendix bursae; ductus bursae constricted to $1 / 2$ width immediately posterior to ostium bursae; ostium bursae, ductus bursae, and posterior $1 / 4$ of corpus bursae sclerotized. Abdominal segment eight (A8) lightly sclerotized except for two large triangular heavily-sclerotized postvaginal plates, tapered posteriorly and partially fused where they meet. Posterior apophyses $2 \times$ as long as lateral length of A8 and $1.5 \times$ as long as anterior apophyses. Anal papillae as long as lateral width, truncated posteriorly, covered with short setae.

Distribution and biology. Baniana minor occurs in open woodland/grassland scrub habitat in southeastern Arizona and also occurs, probably in similar habitat in Guanacaste Province, Costa Rica. Adults have been collected between mid-July and late August in Arizona. Costa Rican records are from April, May, September, November, and December. 

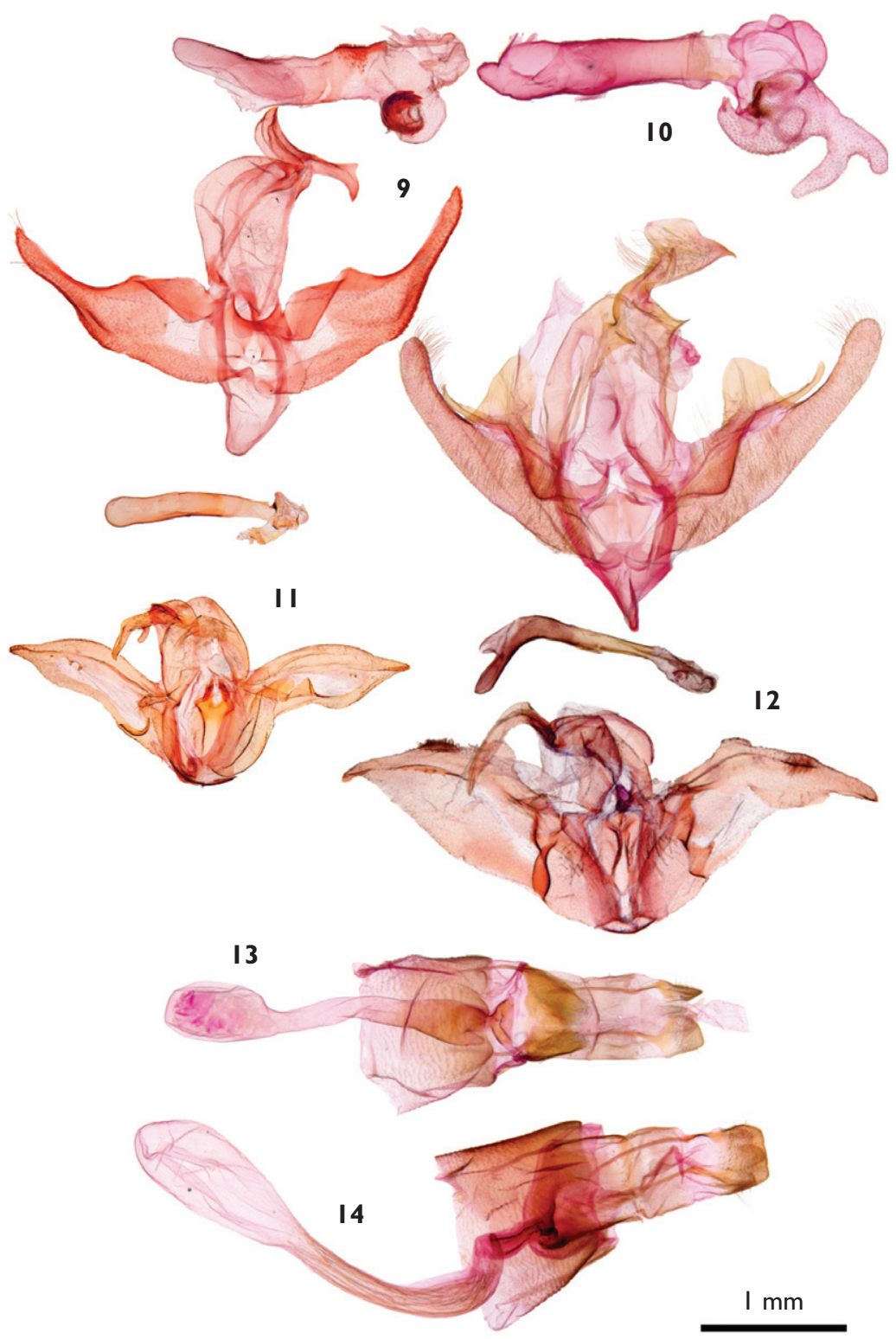

Figures 9-14. Genitalia of Anobinae. 9 Anoba trigonoides, male genitalia (Lara, Venezuela) 10 Deinopa delinquens, male genitalia (Amazonas, Brazil) I I Baniana minor, male genitalia (Santa Cruz Co., Arizona, USA) I 2 Baniana gobar, male genitalia (Sinaloa, Mexico) I 3 Baniana minor female genitalia (Santa Cruz Co., Arizona, USA) I4 Baniana gobar, female genitalia. (Sinaloa, Mexico)

Remarks. Singleton specimens of undescribed species from Veracruz, Mexico and Guanacaste, Costa Rica, indicate that there are several additional undescribed species of Baniana in southern Mexico and Central America. 


\section{Acknowledgements}

We thank Jocelyn Gill for help in the preparation of genitalia, images, and the plates. We thank Cliff Ferris (CDF), Martin Honey (BMNH), Jim Miller (AMNH), Mike Pogue (USNM), and Bo Sullivan (JBS) for providing us access to specimens in their care. Cliff Ferris and Gary Anweiler reviewed the manuscript. Bo Sullivan was very helpful with specimens, images, and insights in our many discussions on the classification of the Anobinae.

\section{References}

Holloway JD (2005) The moths of Borneo: Family Noctuidae, subfamily Catocalinae. Malayan Nature Journal 58: 1-529.

Lafontaine JD (2004) Noctuoidea: Noctuidae (part) - Agrotini. In: Hodges RW (Ed) The Moths of North America. Fascicle 27.1. The Wedge Entomological Research Foundation, Washington. 394 pp.

Lafontaine JD, Schmidt BC (2010) An annotated check list of the Noctuoidea (Insecta: Lepidoptera) of North America north of Mexico. ZooKeys 39: 1-239.

Poole RW (1989) Lepidopterorum Catalogus (New Series). Fascicle 118 Noctuidae, Parts 1-3. E.J. Brill, New York, xii $+1-1314$

Walker F (1858) List of the specimens of lepidopterous insects in the collection of the British Museum 15: 1521-1888. Edward Newman, London. 